\title{
FRAGMENTOS POÉTICOS DE MECENAS: TRADUÇÃO E COMENTÁRIO
}

\author{
Eduardo Henrik AUBERT ${ }^{1}$
}

\section{http://dx.doi.org/10.21165/gel.v18i2.3144}

Resumo: Este artigo oferece uma tradução e um comentário de todos os fragmentos poéticos atribuídos a Caio Clínio Mecenas (c. 70 a.C. - 8 a.C.), o famoso patrono das letras na época augustana, menos conhecido por sua atividade de escritor. O comentário visa a analisar a matéria e a elocução de Mecenas, com especial atenção para as interrelações entre a experiência neotérica e aquela dos poetas augustanos. A análise sugere que, ao identificar uma tensão produtiva entre esses empreendimentos poéticos, a atividade dos escritores do círculo de Mecenas também pode ser mais bem compreendida como experiência histórica complexa. Em apêndice, estão traduzidos ainda todos os fragmentos de prosa supérstite de Mecenas.

Palavras-chave: Literatura latina. Fragmentos. Período augustano. Mecenas. Neoterismo.

1 Universidade de São Paulo (USP), São Paulo, São Paulo, Brasil; eduardo.aubert@usp.br; http://orcid.org/0000-0002-7562-7057 
- Fragmentos poéticos de Mecenas: tradução e comentário

\section{THE POETIC FRAGMENTS OFMAECENAS: TRANSLATION AND COMMENTARY}

Abstract: This article provides a translation and commentary of all the poetic fragments attributed to Caius Clinius Maecenas (c. 70 b.C. - 8 b.C.), the renowned patron of letters of the Augustan age that is lesser known for his activity as a writer. The commentary aims at analyzing Maecenas' subject matter and diction and focuses especially on the interconnections between the Neoteric experience and that of the Augustan poets. It proposes that by identifying a dynamic tension between those poetic endeavors, the activity of the writers of Maecenas' circle can also be envisaged as a multilayered historical experience. All the surviving fragments of Maecenas' prose are translated in an appendix.

Keywords: Latin literature. Fragments. Augustan age. Maecenas. Neoterism.

\section{Introdução}

A história da poesia latina pode ser pensada, tal como aparece para o estudioso moderno, como uma planície obscura, com pequenos oásis luminosos, tão relevantes são as perdas que permitiriam entender o conjunto da paisagem. Tome-se o caso da poesia lírica. Embora Horácio se apresente como inovador nesse domínio - e de fato, em muitos aspectos, parece tê-lo sido -, conforme se depreende, por exemplo, da abertura de seu livro terceiro das Odes, Pompônio Porfirião, um gramático que talvez tenha vivido nos séculos II-III d.C., lembra-nos que a história é mais complexa do que isso, ao comentar Hor.Carm.3.1.2 (o lema carmina prius non audita):

Romanis utique non prius audita, quamuis Laeuius lyrica ante Horatium scripserit; sed uidentur illa non Graecorum lege ad lyricum charactere exacta. (MEYER, 1874, p. 75). [cantos] ainda não ouvidos, em todo caso, pelos romanos, ainda que Lévio tenha escrito [cantos] líricos antes de Horácio; mas eles não parecem ser realizados em estampa lírica, segundo a lei dos gregos.

Infelizmente, de Lévio, tido como iniciador da lírica alexandrina em Roma², restam apenas cerca de 60 versos, muitos incompletos e com pouco contexto, pois foram preservados sobretudo por gramáticos (COURTNEY, 1993, p. 118-143). Seria o pioneiro - ou, como é mais prudente em tais casos, um dos pioneiros - na introdução, na poesia latina, de determinadas inovações associadas a certa etapa de recepção do alexandrinismo em

2 É a posição de Granarolo (1971); antes ainda, ver Mirmont (1903). 
Roma, em movimento que, coletivamente, compreende-se sob o termo de neoterismo ${ }^{3}$,

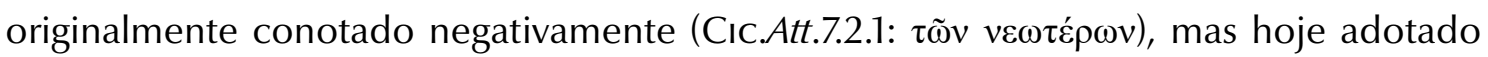
de forma meramente a identificar um conjunto de escritores e traços comuns de sua produção. A relação sugerida aqui entre Lévio e a lírica horaciana condensa muito do que se pode vislumbrar para a relação entre os poetas ativos no final do século I a.C. e seus antecedentes, em geral não conservados.

Excetuados os poetas fragmentários, do vasto movimento neotérico, de capital importância para o desenvolvimento da poesia augustana nas gerações subsequentes, dispomos apenas da obra de Catulo (c. 84 - c. 54 a.C.). Um aspecto importante, no entanto, e bastante negligenciado do neoterismo - como comumente de outras poéticas - é que ele não se esgota quando despontam outras tendências ${ }^{4}$. É nesse sentido que, para Mattiacci (1995, p. 70, tradução nossa ${ }^{5}$ ), é preciso ver o neoterismo como uma corrente substancial, para além de estritos limites cronológicos: "não se trata de escola, mas de uma difusa tendência poética". A conservação precária do material contribui para uma visão distorcida da produção poética, banalizando, para o leitor moderno, a complexa negociação que, a cada ponto, ia se tecendo entre os novos textos e a tradição.

É nesse panorama que talvez se possa compreender uma figura fascinante, dentre os muitos poetas fragmentários do século I a.C., cuja relevância é tanto mais evidente pelo destaque que assumiu como patrono literário em íntima associação com a estruturação da máquina imperial por Augusto. Trata-se de Caio Clínio Mecenas (c. 70 a.C.-8 a.C.)6, que, apesar de ter apoiado a produção poética de Horácio, Propércio e Virgílio, entre outros poetas augustanos, compôs seus próprios versos de acordo com escolhas de matéria e

\footnotetext{
3 Em apertadíssima síntese, sobre as características dos neotéricos, escreveu Jean Granarolo (1972, p. 298, tradução nossa): "Se o termo 'escola' nos parece um pouco manchado de anacronismo no plano da história literária, não nos vem um momento sequer ao espírito contestar as afinidades profundas que uniam todos esses poetas de vanguarda em seu grande combate para aclimatar o alexandrinismo em Roma: conquista da individualidade conjuntamente com uma doctrina compreendida ao mesmo tempo como 'erudição' e como 'gosto' delicado, nascido da cultura assim como da experiência, repúdio dos grandes gêneros em prol do poema tenue et breue; busca da uarietas, da concinnitas e da urbanitas; ideal de lepos [...], que apenas lhes parece possível de ser realizado ao preço de um máximo labor limae". No original: "Si le terme d'école nous semble quelque peu entaché d'anachronisme sur le plan de l'histoire littéraire, il ne nous vient pas un instant à l'esprit de contester les affinités profondes qui unissaient tous ces poètes d'avant-garde dans leur grand combat pour acclimater à Rome l'alexandrinisme: conquête de l'individualité allant de pair avec une doctrina entendue à la fois au sens d"érudition' et au sens de 'goût' délicat, né de la culture autant que de l'expérience ; répudiation des grands genres au profit du poema tenue et breue; recherche de la uarietas, de la concinnitas et de l'urbanitas; idéal de lepos [...], qui ne leur apparaissait réalisable qu'au prix d'un maximum de labor limae".

4 Apenas a visão oposta, de um inexorável "progresso" sustenta ideia como a de que Mecenas teria querido "disciplinar e depurar seu alexandrinismo impenitente" (ANDRÉ, 1983, p. 1776, tradução nossa). No original: "de discipliner et d'épurer son alexandrinisme impénitent".
}

5 No original: "non di scuola si tratta, bensì di una diffusa tendenza poetica".

6 Sobre essa personagem, cf. André (1967); Avallone (1962). Uma salutar consideração crítica das fontes em Costa (2015). 
de elocução que dialogam muito estreitamente (ou melhor, muito explicitamente) com o movimento neotérico - ainda que, como se verá, fosse profundamente cônscio do que se fazia à sua volta.

Embora talvez superdimensionada, a ideia de que "o ministro de Augusto está presente, em filigrana por detrás de toda a poesia de sua época" (ANDRÉ, 1983, p. 1765)7, sem dúvida tem ao menos valor metonímico, para remeter ao problema da relação daqueles poetas com a tradição com que se defrontavam, especificamente com a experiência neotérica.

A despeito do pouquíssimo que resta de texto de Mecenas, para Mattiacci (1995, p. 67 , tradução nossa $\left.{ }^{8}\right)$ :

[...] os fragmentos que chegaram até nós são suficientes para que se entrevejam predileções expressivas e temáticas, que se diferenciam substancialmente daquelas dos poetas que ele protegeu e de quem solicitou uma produção de forte compromisso ideal a serviço do principado.

Do ponto de vista da elocução, Mattiacci (1995, p. 68) destaca o uso de termos raros e a dissociação da ordem habitual das palavras, contribuindo para um preciosismo "ainda mais trabalhado e estudado do que o dos próprios neóteroi, aspecto que certamente constitui um unicum relativamente ao gosto da época em que foram compostos" (MATTIACCI, 1995, p. 68, tradução nossa) $)^{9}$. Ponto relevante porque destaca que, entendido o neoterismo como uma tendência de cronologia ampliada, Mecenas não pode ser tido por mero imitador servil do passado, mas, no mínimo, foi representante ativo de uma tradição que manipula e transmite ao mesmo tempo em que transforma. É nesse sentido que talvez devamos entender a afirmação de que "a experiência poética do grande magnata etrusco representa uma primeira etapa importante no longo processo de evolução e transformação do neoterismo na poesia latina" (MATTIACCI, 1995, p. 83, tradução nossa) ${ }^{10}$.

7 No original, mais amplamente: “Qu'il s'agisse d'un commerce subtil d'allusions, comme dans les 'Géorgiques', ou de dédicaces explicites des grandes œuvres d'Horace, ou encore d'invites quelques peu ambiguës, tel le haud mollia iussa, le ministre d'Auguste est présente en filigrane derrière toute la poésie de son temps".

8 No original: "i frammenti a noi giunti sono sufficienti a farci intravedere predilezioni espressive e tematiche, che si differenziano sostanzialmente da quelle dei poeti che egli protesse e di cui sollecitò una produzione di forte impegno ideale al servizio del principato".

9 No original: "ancor più ricercata e studiata di quella degli stessi neoteroi, aspetto che costituisce sicuramente un unicum rispetto al gusto dell'età in cui essi furono composti".

10 No original: "I'esperienza poetica del grande magnate etrusco rappresenti una prima importante tappa nel lungo processo di evoluzione e trasformazione del neoterismo nella poesia latina". 
Mais concretamente, é, evidentemente, correta a apreciação de Hollis (2007, p. 318, tradução nossa"1):

A influência de Catulo é quase onipresente em Mecenas: no metro (hendecassílabos em 185 [aqui fragmento 2] e 186 [fragmento 3], priapeu em 187 [fragmento 4], galiambos em 188 e 189 [fragmentos 5 e 6]), na matéria (188 e 189 [fragmentos 5 e 6]) e na fraseologia (note como, nos três versos de 186 [fragmento 3], ele combina dois dos mais famosos poemas de Catulo).

Do ponto de vista métrico, deve-se destacar que, entre os fragmentos supérstites, ao lado do hexâmetro e do falécio, mais comuns entre os neotéricos, Mecenas escreveu também nos metros priapeu e galiâmbico, atestados especificamente em Catulo. Evidentemente, trata-se de indício relevante de um laço mais forte com aquele poeta (seu "modelo", MAKOWSKI, 1992, p. 31)12, embora a situação fragmentária dos demais poetas sugira a necessidade de mais cautela contra um julgamento peremptório.

No entanto, reduzir a produção de Mecenas a um neoterismo de verve catuliana seria, ao que tudo indica, redutor. Algumas particularidades, para além do metro, aparecem em outros aspectos da elocução. Sua escrita se destaca sobretudo por uma manipulação constante da ordem das palavras, pela busca de simetrias, inversões e toda a sorte de correspondência, de modo tal que não se encontra paralelo no corpus neotérico, nem no catuliano. É esse um dos principais motivos da crítica que Sêneca, no século seguinte, dirigiu aos escritos de Mecenas, especialmente à sua prosa (cf. apêndice). Note-se, contudo, que a manipulação da ordem das palavras para efeitos de sentido era elemento central da poesia horaciana (HASEGAWA, 2018; HASEGAWA, 2019), e, nesse sentido, o "neoterismo" de Mecenas não se pode ter por anacrônico, mostrando-se antes cônscio da própria posição histórica. As tensões, próprias à efetiva densidade histórica de uma experiência, vão assim tomando relevo.

Ponto importante no manejo da língua é que os limites entre prosa e poesia são relativizados ${ }^{13}$. Afinal, conforme nota Mattiacci (1995, p. 81-82, tradução nossa ${ }^{14}$ ):

\footnotetext{
11 No original: "The influence of Catullus is almost overwhelming, in Maecenas' metres (hendecassylables in 185 and 186m Priapean in 187, galliambics in 188 and 189), subject matter (188 and 189, the Magna Mater), and phraseology (note how, in three lines of 186, he combines two of Catullus' most famous poems).".

12 No original: "model".

13 Embora não reste prosa de um contemporâneo como Horácio, cujo agenciamento formal do texto parece ter sido de especial relevância para Mecenas, essas fronteiras (ou esse questionamento de fronteiras) sem dúvida colocam problema semelhante ao que, no interior mesmo do texto poético, Horácio propunha ao aproximar o hexâmetro da sátira de uma elocução prosaica (GOWERS, 2012, p. 22-24).

14 No original: "La prosa numerosa di Mecenate, preziosa nella scelta dei vocaboli, audace nella loro collocazione e nelle immagini, mostra confini incerti con la poesia; anch'essa conserva trace di un realismo
} 
[...] a prosa numerosa de Mecenas, preciosista na escolha das palavras, audaz em sua colocação e nas imagens, mostra limites incertos com a poesia; também ela conserva indícios de um realismo rústico e amaneirado, revelando ademais um sentimento vivaz da natureza retratada em imagens impressionísticas e subjetivas.

No que tange à matéria, a poesia de Mecenas, diante do que se pode vislumbrar dos neotéricos, parece desenvolver com especial afinco temas relacionados à corporalidade e à morte. Isso a tal ponto que um crítico perspicaz como Courtney não escapou aos riscos de um psicologismo inverificável: "o preciosismo e a neurose do autor aparecem com força nos fragmentos" (1993, p. 276, tradução nossa) ${ }^{15}$. Conforme sugerimos adiante, em comentário aos fragmentos 4 e 8 , talvez esse tema não se deva compreender, conforme quer certa parcela da crítica, em razão de motivações psicológicas - imperscrutáveis -, mas como desenvolvimento engajado de motivos que, menos proeminentes, podiam já ser encontrados nos neotéricos. Ademais, a atestação de outras matérias - o culto a Cibele, a sodalitas, etc. - alerta para a possibilidade de uma produção bastante variegada, com o peso de certas tópicas certamente enviesado pelo filtro seletivo das citações.

Com resgatar a poesia de Mecenas para o leitor brasileiro, esperamos sobretudo contribuir para a reflexão sobre a complexa encruzilhada histórica em que se situou um dos momentos mais fecundos da produção poética latina, que sem dúvida se compreenderia muito melhor não se tivesse perdido tanto material - mas que, também indubitavelmente, compreende-se ainda menos bem se desprezamos as pistas pertinentes de que dispomos.

Este trabalho tem o simples propósito de traduzir os fragmentos supérstites da poesia de Mecenas, adicionando-Ihes alguns elementos de comentário para incrementar sua compreensão, à luz do problema central da tensão entre poesia neotérica e poesia augustana. Trata-se de tradução semântica, sem nenhuma pretensão de recriar poeticamente Mecenas em português. Julgamos também relevante traduzir, em apêndice, os fragmentos de prosa de Mecenas, material que merece exame à parte, em ocasião propícia - assim como os muitíssimos testimonia relativos a Mecenas -, mas, reunindo todo o material textual atribuído àquela personagem, oferecemos plataforma coesa para ulteriores reflexões, sem correr o risco da dispersão ${ }^{16}$.

rustico e manierato, rivelando altresì un vivace sentimento della natura ritratta in immagini impressionistiche e soggettive".

15 No original: "The preciosity and neuroticism of the author come through strongly in the fragments". Para André, os fragmentos seriam mesmo "espelho de uma alma" (1983, p. 1770, tradução nossa). No original: "miroir de l'âme".

16 Servimo-nos da edição dos fragmentos de Mecenas por Courtney (1992), cotejando-a com a de Blänsdorf (2011). Catulo é citado conforme a edição de Mynors (1958), e Horácio, naquela de Shackleton-Bailey (2008). Os demais autores antigos estão nas edições listadas na bibliografia. 


\section{Os fragmentos poéticos de Mecenas}

\begin{tabular}{|l|l|}
\hline & 1 CHARIS.79 K=100 B \\
\hline $\begin{array}{l}\text { Catinus masculino genere dicitur, ut Maecenas } \\
\text { in X ait: }\end{array}$ & $\begin{array}{l}\text { Catinus se diz no gênero masculino, como fala } \\
\text { Mecenas no [livro?] X: }\end{array}$ \\
\hline ingeritur fumans calido cum farre catinus. & $\begin{array}{l}\text { uma panela fumegante com espelta quente é } \\
\text { despejada. }\end{array}$ \\
\hline
\end{tabular}

metro: hexâmetro dactílico

Courtney chama atenção para a menção ao numeral X, na introdução à citação, conjecturando que, diante de uma edição das obras reunidas de Mecenas (1993, p. 276), poderia se tratar de referência à ordem de livros - ou mesmo, quiçá, de poemas em um libelo. Não há, contudo, outro fragmento transmitido em situação comparável.

A cena é afim à sátira e à comédia (menos pertinente a conexão proposta com a bucólica ou com a elegia rústica, ANDRÉ, 1983, p. 1769)17. Segundo Hollis (2007, p. 319, tradução nossa $\left.{ }^{18}\right)$, trata-se provavelmente "não de um grande banquete", mas de cena como a de Juvenal, louvando a parcimônia dos antigos romanos: amplior et grandes fumabant pultibus ollae (Juv.14.171). A relação com uma forma de mingau - traduzimos aqui far como "espelta", para diferenciá-lo de puls - parece justamente significativa ${ }^{19}$, por seu caráter tópico (cf., e.g., LUCIL.197, 502 e 711).

Com a sátira latina, o fragmento compartilha não só a escolha pela matéria, mas também a composição hexamétrica. Para além das aliterações (em /f/: fumans... farre; em / $/$ : calido cum... catinus), possivelmente vinculadas a modelos satíricos como Ênio e Lucílio, talvez o agenciamento de fumans... catinus (o continente), a englobar calido cum farre (o conteúdo), esteja a indicar a exploração de uma sintaxe mimética, afim à produção de Horácio.

Notável ainda a disposição do adjetivo fumans no fim do primeiro hemistíquio, com o substantivo correspondente colocado ao fim do verso; trata-se de expediente comum em Catulo, imitando a disposição praticada por autores helenísticos (cf., e.g., Catul.64.2, dicuntur liquidas || Neptuni nasse per undas, e Catul.64.20, tum Thetis humanos || non despexit hymenaeos).

17 Para Mattiacci, a inspiração do fragmento poderia provir ainda dos pré-neotéricos, especialmente de obras como os Mimiambi de Mácio e os Idyllia de Sueio (1995, p. 80), com uma nítida ascendência alexandrina, mas a relação com a sátira talvez seja imediatamente mais decisiva.

18 No original: "not a grand banquet".

19 Catinus figura, em Varrão, como nome de um receptáculo em que se colocava mingau (VAR.L..5.25). 


\begin{tabular}{|l|l|}
\hline & 2 IsıD.Orig.19.32.6 (anulus): \\
\hline $\begin{array}{l}\text { Thynius purus est, primum in Bithynia } \\
\text { fabricatus, quam olim Thyn<i>am uocabant. } \\
<\text { Maecenas ad> Flaccum (Lunderstedt 58 } \\
\text { Flaccus codd.): }\end{array}$ & $\begin{array}{l}\text { O tínio é puro, primeiro fabricado na Bitínia, } \\
\text { que antes chamavam Tínia. Mecenas a } \\
\text { [Horácio] Flaco: }\end{array}$ \\
\hline $\begin{array}{l}\text { lucente<s }>\text { mea uita, nec smaragdos } \\
\text { beryllos neque, Flacce mi, nitentes } \\
\text { nec percandida margarita quaero } \\
\text { nec quos Thynica lima perpoliuit } \\
\text { anellos nec iaspios lapillos. }{ }^{20}\end{array}$ & $\begin{array}{l}\text { Nem esmeraldas reluzentes, minha vida, } \\
\text { nem berilos brilhantes, meu Flaco, para mim, } \\
\text { nem uma pérola branquíssima peço, } \\
\text { nem os aneizinhos que a lima tínia poliu à } \\
\text { perfeição, } \\
\text { nem joiazinhas de jaspe. }\end{array}$ \\
\hline
\end{tabular}

metro: hendecassílabo

Esse fragmento, razoavelmente amplo, convoca um dossiê bastante robusto. Há interessante trecho de carta de Augusto a Mecenas, preservado em Macróbio (MACr.2.4.12) e enquadrado por comentário sobre a elocução, de interesse imediato para a passagem:

\begin{tabular}{|c|c|}
\hline & MACR.2.4.12 \\
\hline 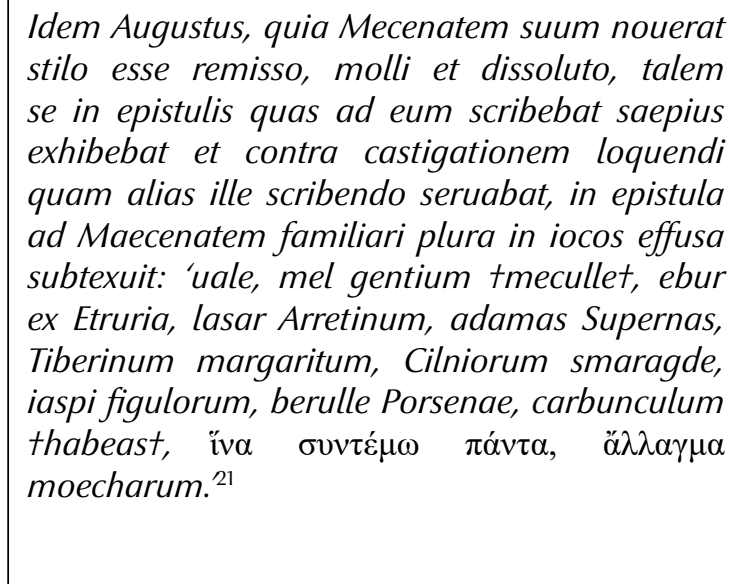 & $\begin{array}{l}\text { O mesmo Augusto, sabendo que Mecenas, } \\
\text { seu amigo, tinha um estilo negligente, } \\
\text { mole e frouxo, nas cartas que Ihe escrevia, } \\
\text { frequentissimamente conformava o seuaodele } \\
\text { e, contrariamente à poda da expressão que } \\
\text { habitualmente empregava ao escrever outras, } \\
\text { em uma carta pessoal a Mecenas, entreteceu } \\
\text { muitas palavras em gracejos: "Adeus, mel dos } \\
\text { povos tda Medúliat, marfim da Etrúria, laser } \\
\text { de Arezzo, diamante do Adriático, pérola } \\
\text { do Tibre, esmeralda de Cilniana, jaspe dos } \\
\text { ceramistas, berilo de Porsena, carbúnculo } \\
\text { tde Hadriat; para dizer tudo resumidamente: } \\
\text { recompensa das prostitutas". }\end{array}$ \\
\hline
\end{tabular}

Mattiacci (1995, p. 68, n. 322; também KASTER, 2011, p. 351, n. 58) entende que "é provável que o fragmento de Augusto conservado porMacróbio aluda, em chave paródica, aos preciosos versiculi do fragmento 2", o que nos parece bastante verossímil à luz das quatro joias mencionadas conjuntamente em ambos os textos (esmeralda, berilo, pérola e jaspe; contra: HOLLIS, 2007, p. 319). A preservação de um possível diálogo não deve

20 Para importante crítica às lições do texto, cf. Rodríguez-Pantojas (1973).

21 Como se nota pelos obelos, o texto traz uma série de incertezas. A tradução espelha algumas conjecturas, registradas no aparato de KASTER, 2011, p. 348-350, notadamente: Medulliae, por meculle; Hadriae, por habeas.

22 No original: "mi sembra probabile che il frammento augusteo conservato da Macrobio alluda in chiave parodica ai preziosi versiculi del fr. 2". 
espantar, havendo vários liames sugestivos entre textos conservados, nomeadamente entre composições de Horácio e os fragmentos de Mecenas, como veremos ainda no caso do fragmento 3 , infra ${ }^{23}$.

Encorpando o dossiê, Suetônio, ao discutir a elocução de Augusto, fornece o que se pode tomar quase como comentário à passagem em Macróbio (SuEt.Aug.86.1-2):

\begin{tabular}{|c|c|}
\hline & SUET.Aug.86.1-2 \\
\hline $\begin{array}{l}\text { Genus eloquendi secutus est elegans et } \\
\text { temperatum, uitatis sententiarum ineptiis atque } \\
\text { concinnitate et 'reconditorum uerborum,' ut ipse } \\
\text { dicit, 'fetoribus', praecipuamque curam duxit } \\
\text { sensum animi quam apertissime exprimere. } \\
\text { [... Cacozelos et antiquarios ut diuerso genere } \\
\text { uitiosos, pari fastidio spreuit exagitabatque } \\
\text { nonnumquam, in primis Maecenatem suum, } \\
\text { cuius 'myrobrechis', ut ait, 'cincinnos' usque } \\
\text { quaque persequituretimitando periocum irridet. }\end{array}$ & $\begin{array}{l}\text { Ele [Augusto] adotou um estilo elegante } \\
\text { e temperado, evitando as parvoíces das } \\
\text { máximas, os arranjos balanceados e, como } \\
\text { ele mesmo diz, "o fedor das palavras } \\
\text { recônditas"; sua principal preocupação esteve } \\
\text { em expressar o sentido do pensamento de } \\
\text { forma claríssima. [...] Com igual desdém, } \\
\text { desprezou os de mau gosto e os antiquários, } \\
\text { viciosos de modos diversos, e os provocava } \\
\text { às vezes, especialmente seu caro Mecenas, } \\
\text { cujas "madeixas embebidas de unguentos } \\
\text { perfumados", como disse, ele contrafaz e } \\
\text { ridiculariza, imitando zombeteiramente. }\end{array}$ \\
\hline
\end{tabular}

Se aqui Augusto destaca um composto grego misturado a palavra latina como marca da dicção de Mecenas - como no próprio fragmento 2, os nomes das pedras recheiam o texto de palavras não latinas ${ }^{24}$ - destaca-se, no fragmento em exame, outro aspecto estrutural da elocução, a saber, "a ordem de palavras [...] extraordinariamente artificial" (HOLLIS, 2007, p. 320, tradução nossa) ${ }^{25}$, mas que, no caso, produz uma inversão termo por termo da ordem das palavras entre o verso 1 e o verso $2^{26-27}$, não apenas com o quiasmo dos adjetivos e dos substantivos (lucentes... smaragdos/ beryllos... nitentes), notável pela

23 Em todo caso, Bradshaw levantou a hipótese de que Hor.Carm.3.8, de Horácio, conteria uma paródia do estilo de Mecenas (1970). Para o autor, "Horácio está fazendo uma brincadeira com seu amigo, ao caricaturar o estilo do próprio Mecenas," produzindo "meceneanismos" (1970, p. 148, tradução nossa). No original: "Horace is making gentle fun of his friend by caricaturing Maecenas' own style [...] 'Maecenasianisms'".

24 Note-se, no pequeno fragmento do que parece ser texto de Mecenas (myrobrechis cincinnos), o apontamento de um composto grego transliterado em latim, acoplado a uma palavra latina (cf. a crítica aos neotéricos precisamente em razão dessa mistura em HoR.Sat.1.10.17-24).

25 No original: "the word order is extraordinarily artificial".

26 Razão que levou Courtney a emendar beryllos mihi Flacce, nec nitentes, em Isidoro, por beryllos neque, Flacce mi, nitentes, emenda aqui adotada.

27 Note-se, nesse arranjo, a prolepse de lucentes, no verso 1, antes de nec e de todo o sintagma mea uita, o que se repete com beryllos no verso 2, assim como, já ao final do trecho, a interrupção do sintagma nec anellos pela oração relativa quod Thynia lima perpoliuit. Courtney (1993, p. 276, tradução nossa) afirma "não ter paralelo para o adiamento de nec, neque quando ligam uma lista de substantivos". No original: "I do not have a good parallel for postponement of nec, neque when it links a list of nouns". 
- Fragmentos poéticos de Mecenas: tradução e comentário

posição inicial e terminal e pelos homeoteleutos (em -es e em -os), mas também nas posições de nec e neque e enfim dos vocativos correspondentes mea uita e Flacce mi.

Essa escrita, propositadamente arrevesada, é um dos pontos fundamentais da crítica de Sêneca: haec uerba... tam contra consuetudinem omnium posita ("estas palavras [...], dispostas tão contrariamente ao costume de todos", SEN.Ep.114.7; cf., ainda, SEN.Ep.114.15)28. Porém, a ordem não é simplesmente arrevesada; ela é desenhada em uma variedade que espelha, no ornato verbal, os ornamentos de cuja variedade trata o poema.

Essas listas de ornamentos são elas mesmas tópicas, podendo-se recuperar relevante precedente (pré-)neotérico em Lévio: aut / nunc quaepiam alia te ilico / Asiatico ornatu affluens / aut Sardiano aut Lydio / fulgens decore et gratia / pellicuit ("ou agora alguma outra sem demora, transbordando com adorno asiático ou com sardo ou lídio enfeite e graça reluzindo, te seduziu", COURTNEY, 1993, p. 146). Em Cina, atesta-se ainda o interesse pela temática das pedras preciosas (cf. COURTNEY, 1993, p. 222; ver, também, Hor.Carm.1.31.3-7).

Há, ademais, importantes ecos catulianos no fragmento. As margaritae, percandidae - primeira característica das pérolas mencionadas por Plínio o Velho (Puin.Nat.9.112) ecoam o perluciduli... lapidis ("de uma pedra transparentezinha", CATUl.69.4), segundo nota Hollis (2007, p. 32029), chamando atenção para o prefixo per como reforço da característica de uma pedra preciosa. Relevante também que Catulo tenha se servido ao mesmo tempo do prefixo de intensificação per e do diminutivo, resultando, como nota Merrill (1893, p. 192, n. $4^{30}$ ), em um "ä $\alpha \alpha \xi \lambda \varepsilon \gamma o ́ \mu \varepsilon v o v$ como diminutivo". Afinal, na última linha, também em veio catuliano, Mecenas se vale de dois diminutivos: anellos e lapillos.

O fragmento sem dúvida está incompleto, pois tem estrutura de início de um priamel, faltando declarar aquilo que Mecenas efetivamente quaerit. Muito provavelmente, tratavase de um desdobramento de mea uita. Para Courtney (1993, p. 277, tradução nossa ${ }^{31}$ ), a expressão "sugere um elemento erótico nos sentimentos de Mecenas por Horácio", o que novamente parece psicologismo sem aptidão de ser comprovado, devendo-se antes inserir na codificação do endereçamento mútuo, com convenções repetidamente aplicadas (em Horácio, dirigindo-se a Mecenas, lê-se meae... partem animae, Hor.

\footnotetext{
28 Para Mattiacci, o esquema sintático seria de matriz horaciana, com referência a Hor.Carm.1.31 e Hor. Carm.2.18 (1995, p. 78). Mas, parece que, em tais casos, à parte a sucessão de orações coordenadas com non e nec, não há sinal de um arrevesamento da ordem das palavras comparável ao que se tem em Mecenas.

29 Cf. SEN.Ep.90.45: non aurum nec argentum nec perlucidos lapides ("nem ouro, nem prata, nem pedras transparentes").

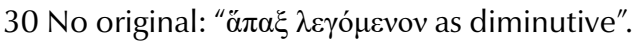

31 No original: "suggests an erotic element in Maecenas' feelings for Horace".
} 
Carm.2.17.5; já no célebre Hor.Carm.1.3.8, com relação a Virgílio). Especificamente mea uita é sintagma que aparece duas vezes em Catulo (45.13: 'sic' inquit 'mea uita Septimille; 109.1: iucundum, mea uita, mihi proponis amorem).

Trata-se de ponto de primeira importância, pois, como o fragmento 4, infra, essa codificação parece encerrar os termos de uma correspondência poética, podendo levar à "inferência de que os dois [Horácio e Mecenas] desenvolveram, ao longo dos anos, um diálogo poético estendido" (MCDERMOTT, 1982, p. 217, tradução nossa) ${ }^{32}$. Aliás, a recodificação de tópica bem assentada nos precedentes neotéricos, segundo o que parece ser uma sintaxe propositadamente voltada a comunicar sentidos, talvez encontre sua plena explicação justamente como elemento de um diálogo poético com Horácio, funcionando assim como relevante declaração (de) poética.

\begin{tabular}{|l|l|}
\hline & 3 SUET.Vit.Hor. \\
\hline $\begin{array}{l}\text { Maecenas quantopere eum dilexerit satis } \\
\text { testatur illo epigrammate: }\end{array}$ & $\begin{array}{l}\text { O quanto Mecenas gostava dele é bem } \\
\text { atestado por aquele epigrama: }\end{array}$ \\
\hline $\begin{array}{l}\text { ni te uisceribus meis, Horati, } \\
\text { plus iam diligo, tu tu<u>m sodalem } \\
\text { tnimiot uideas strigosiorem. }\end{array}$ & $\begin{array}{l}\text { Se eu já não te amo mais que às minhas } \\
\text { entranhas, } \\
\text { Horácio, verás teu companheiro, } \\
\text { mais esquálido que ao excesso. }\end{array}$ \\
\hline
\end{tabular}

metro: hendecassílabo

Como o fragmento precedente, estes versos apontam para o relevante diálogo poético entre Mecenas e Horácio. Os versos 1 e 2 parecem ser emulação de passo de Catulo: ni te plus oculis meis amarem (CATUl.14.1), de modo que Courtney (1993, p. 27733) questiona, de forma irônica: "pode-se perguntar como Horácio se sentia ao ser interpelado em termos catulianos". Mattiacci $\left(1995\right.$, p. $75^{34}$ ) pensa que se trata de "forte alusão" a Catulo, desenvolvendo o questionamento de Courtney e respondendo, em parte, a ele: "em ambos os casos trata-se de [hendecassílabos] falécios, e a retomada parece jocosa, seja pela substituição de uisceribus a oculis, seja porque, em termos catulianos, quem é

32 No original: "inference that the two men carried on over the years an extended poetic dialogue".

33 No original: "One wonders how Horace felt at being addressed in Catullan terms".

34 No original: "forte allusione". 
chamado é o próprio poeta empenhado na luta contra os maus imitadores de Calvo e Catulo (cf. Hor.Sat.1.10.18ss)" (MATTIACCI, 1995, p. 75) 35-36-37.

O trecho entre óbelos levanta diversas dificuldades (ROSTAGNI, p. 112, n. 12; KÓRISZ, 2007). Os manuscritos de Suetônio variam, com nimio aparecendo mais frequentemente. Uma proposta extravagante, mas muito amplamente aceita, substitui nimio por hinnulo, com base no fato de que strigosus é frequentemente usado para falar de cavalos maltratados (Lıv.27.47.1, Gel.4.20.11)38. Além da dificuldade métrica levantada pelas restaurações propostas - pois o hendecassílabo perderia a base espondaica -, parece-nos que nimio seja perfeitamente aceitável no contexto, a exemplo de Hor.Carm.1.33.1: ne doleas plus nimio.

Em conjunção com o fragmento 2, este pequeno epigrama sugere a experiência neotérica como tema privilegiado de uma discussão de poética entretida por essas personagens.

\begin{tabular}{|l|l|}
\hline & 4 SEN.Ep.101.10-11 \\
\hline $\begin{array}{l}\text { inde illud Maecenatis turpissimum uotum quo } \\
\text { et debilitatem non recusat et deformitatem et } \\
\text { nouissime acutam crucem, dummodo inter } \\
\text { haec mala spiritus prorogetur: }\end{array}$ & $\begin{array}{l}\text { Daí aquele desejo tão abjeto de Mecenas, pelo } \\
\text { qual não recusa a fraqueza, a deformidade e, } \\
\text { enfim, uma cruz pontiaguda, desde que, em } \\
\text { meio a tais males, o seu sopro seja prorrogado: }\end{array}$ \\
\hline
\end{tabular}

35 No original: "si tratta in entrambi casi di faleci e la ripresa sembra giocosa, sia per la sostituzione di visceribus ad oculis, sia perché in termini catulliani è appellato proprio il poeta impegnato nella lotta contro gli scimmiottatori di Calvo e Catullo (cfr. Sat. 1.10.18. sg.)".

36 Hollis, entretanto, duvida do paralelo, pela distinta resolução da condicional na oração principal que se segue em cada caso. Sugere que o passo é mais próximo de outros versos catulianos: ni te perdite amo... / ... / solus in Libya Indiaque tosta / caesio ueniam obuius leoni (Catul.45.3 e Catul.45.6-7) (HOLLIS, 2007, p. 321; MAKOWSKI, 1992, p. 32), com a mesma tópica de desejar um mal a si mesmo se não for verdadeira a declaração amorosa. Evidentemente, seria possível que Mecenas tivesse os dois poemas em mente.

37 No entanto, nem tudo é puro catulianismo. Mattiacci entende que "com tuum sodalem e com termos como ninnio [cf. abaixo] e strigosiorem, já estamos além de Catulo, já nos movemos em direção a módulos artificiosos, entre o arcaico e o popularesco, dos versos novelli" (MATTIACCI, 1995, p. 75). No original: "Ma con tu tuum sodalem e con i termini ninnio e strigosiorem siamo già oltre Catullo, già ci muoviamo verso $\mathrm{i}$ moduli artificiosi, tra l'arcaico e il popolareggiante, dei versi novelli". A despeito da importância da sugestão de Mattiacci, de ver em Mecenas espécie de elo perdido entre o neoterismo e aquele movimento mais tardio, parece-nos que, do ponto de vista da experiência de Mecenas, importa mais particularmente a mescla de distintos níveis de elocução, que é bem atestada na poesia augustana.

38 O diminutivo hinnulus, a partir de hinnus, segundo Courtney (1993, p. 278), "se adaptaria bem à aura catuliana". No original: "would suit the Catullan aura". Mais precisamente, Plínio, em um passo, afirma que um hinnus, o filho de um burro com uma égua, é strigosus (Puin.Nat.8.174). 
[11]

debilem facito manu, debilem pede coxo, tuber adstrue gibberum, lubricos quate dentes: uita dum superest, benest; hanc mihi, uel acuta si sedeam cruce, sustine.
[11]

faze-[me] impotente na mão, impotente no pé, manco,

erige um tumor em uma corcunda, chacoalha os dentes [até que fiquem] bambos:

enquanto resta vida, está [tudo] bem; protege-ma, mesmo que eu esteja posto em uma cruz pontiaguda.

metro: priapeu

Trata-se de raro exemplo de verso priapeu (glicônio seguido de ferecrácio em cada verso), metro usado em CATul.17 e no fragmento 1 de Catulo (este dirigido de fato a Priapo, em forma de hino). Para Costa, seria um epigrama (2009).

A escolha lexical acena para uma elocução baixa: coxo, por exemplo, é um ä $\alpha \alpha \xi$ $\lambda \varepsilon \gamma o ́ \mu \varepsilon v o v$, com correspondente apenas nas línguas neolatinas e mais especialmente no espanhol e no português, provavelmente elementos do sermo cotidianus (MATIACCI, 1995, p. 79). No mesmo sentido pode-se ler benest, conforme nota Hollis, chamando a atenção para Catul.38.1-2 (malest... / malest...). O mesmo se poderia dizer ainda para gibberum, primeiramente atestado em LuCIL.1179. Essa especificidade da elocução dá credibilidade à hipótese de que os versos "são e apenas podem ser satíricos" (MAKOWSKI, 1992, p. 34) ${ }^{39}$, ou melhor, jocosos, e não um "pronunciamento filosófico sério" (MAKOWSKI, 1992, p. $34 ;{ }^{40}$ contra: COSTA, 2009), como Sêneca parece entendê-los.

A simetria na construção dos dois primeiros versos é, como no fragmento 2, notável. No primeiro, nota-se a anáfora debilem, escandindo o verso, com manu e pede se correspondendo semanticamente nos dois hemistíquios, talvez a construir figura polar (a mão e o pé pelo todo dos membros). No segundo verso, novamente cindido em duas metades, o verbo assume posição mediana (adstrue, quate), mas com uma inversão entre a posição do substantivo (tuber, dentes) e do adjetivo (gibberum, lubricos), além das assonâncias entre tuber e lubricos e entre tuber e gibberum. Os dois versos seguintes, no lugar da parataxe daqueles, têm dois períodos compostos, um dos quais desborda o verso, com a prótase inserta no meio da apódose. Talvez se verifique aqui novamente instância de sintaxe mimética, evocando o centro da cruz, onde está a personagem ( $s i$ sedeam) e os seus braços (acuta... cruce $)^{41}$. Pode ser ainda que haja uma onomatopeia em

39 No original: "are and can only be satirical".

40 No original: "serious philosophical pronouncement".

41 Sobre a cruz, cf. Courtney (1993, p. 278-279). 
quate dentes, com as linguodentais /t/ e /d/, de modo semelhante a CATUL.39.1-2 (Egnatius, quod candidos habet dentes, / renidet usque quaque...), com reforço ao fim da velar $/ \mathrm{k} /$, no mesmo sentido ${ }^{42}$.

Dois outros testemunhos podem contribuir para a compreensão do fragmento. $\mathrm{O}$ primeiro é uma citação de trechos da prosa de Mecenas por Quintiliano:

\begin{tabular}{|c|c|}
\hline & Quint.Inst.9.4.28 \\
\hline $\begin{array}{l}\text { Quaedam uero transgressiones et longae sunt } \\
\text { nimis, ut superioribus diximus libris, et interim } \\
\text { etiam compositione uitiosae, quae in hoc } \\
\text { ipsum petuntur, ut exultent atque lasciuiant, } \\
\text { quales illae Maecenatis: 'sole et aurora rubent } \\
\text { plurima'; 'inter sacra mouit aqua fraxinos'; } \\
\text { 'ne exequias quidem unus inter miserrimos } \\
\text { uiderem meas' (quod inter haec pessimum est, } \\
\text { quia in re tristi ludit compositio). }\end{array}$ & $\begin{array}{l}\text { Mas certas transposições são demasiado } \\
\text { longas, como nós dissemos nos livros } \\
\text { precedentes, e às vezes mesmo viciosas } \\
\text { no que respeita à composição, e elas são } \\
\text { buscadas exatamente por essa razão, para } \\
\text { que regozijem e divirtam, como aquelas de } \\
\text { Mecenas: eles enrubescem sob o sol e a mais } \\
\text { plena aurora; entre os freixos, a água agitou as } \\
\text { coisas sagradas; nem mesmo os meus funerais } \\
\text { veja eu, o mais infeliz de todos (entre essas, a } \\
\text { última é a pior, pois a composição brinca em } \\
\text { um assunto triste). }\end{array}$ \\
\hline
\end{tabular}

Como se vê, Quintiliano está, como já Sêneca, a criticar a ordem arrevesada das palavras em Mecenas (certamente as separações de plurima e aurora, na primeira frase, de sacra e aqua, na segunda, e de exequias e meas, na última; MAKOWSKI, 1992, p. 31), entendendo-a, contudo, a nosso ver acertadamente, como forma de jogo (ludit compositio), reprovando especialmente aquela que não é, a seu sentir, decorosa com a matéria lúgubre. Evidentemente, o caso em exame poderia se inserir na mesma categoria, seja pela matéria abordada, seja pelo tratamento que lhe é dispensado.

O segundo testemunho pertinente é o já citado Hor.Carm.2.17, endereçado a Mecenas, em que Horácio tenta acalmá-lo, aparentemente atormentado pela ansiedade com a sua morte, após se recuperar de uma doença ${ }^{43}$. Ao desenvolver o tema da própria morte, que se seguiria se Mecenas morresse (Hor.Carm.2.17.5-12), Horácio está flertando com a tópica meceniana, ainda que para negá-la na sequência. Parece, ao fim e ao cabo, que Horácio esteja a ridicularizar a persona hipocondríaca de Mecenas (note-se, a uma, a relação entre Hor.Carm.2.17.25-26 e Carm.1.20, em que Horácio convida jocosamente o amigo para beber a fim de celebrar a recuperação de uma doença, e, a duas, as lembranças sempre jocosas de Horácio sobre quando esteve próximo da morte: Hor.Carm.2.13; 1.17; 3.4.27; 3.8.7-8).

42 Sugestão que devemos a observação arguta do parecerista anônimo.

$43 \mathrm{Na}$ interpretação de Nisbet e Hubbard, a ode está relacionada tanto com o fragmento poético aqui comentado como com o trecho reportado por Quintiliano (1992, p. 273-274). 
De forma evidentemente muito tênue, limitada pela condição em que Mecenas nos chegou, entrevemos mais uma vez um diálogo poético, em que os autores se apropriam das declarações dos correspondentes apenas para subvertê-las, ou melhor, para convertêlas a seu próprio mundo poético.

\begin{tabular}{|c|c|}
\hline & $\begin{array}{l}\text { 5-6 (+ anon. } 19-20 \text { pp. } 174-5 \mathrm{M}=21-22 \text { pp. } 205- \\
6 \text { B) } \\
\text { [Césio Basso], GLK vi. } 262 \text { : }\end{array}$ \\
\hline Huic pares sunt apud Maecenatem: & Semelhantes a esse, há em Mecenas: \\
\hline $\begin{array}{l}\text { [fr. 5] ades, inquit, o Cybebe, fera montium dea, } \\
\text { ades et sonante ty[m]pano quate flexibile caput. }\end{array}$ & $\begin{array}{l}\text { vem, disse, ó Cibele, deusa feroz das montanhas, } \\
\text { vem e, soando o tímpano, balança a cabeça } \\
\text { flexível. }\end{array}$ \\
\hline $\begin{array}{l}\text { Sed quo magis hic uersus, quod matri sacer est } \\
\text { Ideae, uibrare uideatur, proximum ab ultimo } \\
\text { pede brachysyllabon fecerunt et Graeci et hic } \\
\text { ipse Maecenas iis quos modo rettuli proximum } \\
\text { sic: }\end{array}$ & $\begin{array}{l}\text { Mas, para que esse verso, que é dedicado } \\
\text { à mãe frígia, pareça vibrar mais, os gregos } \\
\text { tornaram o próximo verso catalético, no } \\
\text { último pé, e aqui o próprio Mecenas, no verso } \\
\text { que se segue àqueles que acabo de reportar: }\end{array}$ \\
\hline $\begin{array}{l}\text { [fr. 6] latus horreat flagello, comitum chorus } \\
\text { ululet. }\end{array}$ & $\begin{array}{l}\text { o flanco trema com o chicote, o coro de } \\
\text { companheiros uive. }\end{array}$ \\
\hline Et Catullus (63.2) et ille alterius auctoris: & E Catulo (63.2) e este de outro autor: \\
\hline o qui chelyn canoram plectro regis Italo. & $\begin{array}{l}\text { ó [tu], que dominas a lira canora com o plectro } \\
\text { itálico. }\end{array}$ \\
\hline $\begin{array}{l}\text { Diomedes } 514 \text { galliambum metrum apud } \\
\text { Maecenatem tale est: }\end{array}$ & $\begin{array}{l}\text { Diomedes 514: há um metro galiâmbico em } \\
\text { Mecenas, assim: }\end{array}$ \\
\hline ades... dea. & vem... deusa. \\
\hline ... galliambum aliud ex hoc ipso factum... tale: & $\begin{array}{l}\text { [...] outro verso galiâmbico feito pelo mesmo } \\
{[\ldots] \text { assim: }}\end{array}$ \\
\hline latus... ululet. & flanco... uive. \\
\hline $\begin{array}{l}\text {... ceterum huic metro... simile est illud } \\
\text { neotericum quod est tale: }\end{array}$ & $\begin{array}{l}{[\ldots] \text { outro }[. . .] \text { semelhante neste metro é aquele }} \\
\text { neotérico que é assim: }\end{array}$ \\
\hline rutilos recide crines habitumque cape uiri. ${ }^{44}$ & $\begin{array}{l}\text { corta os cabelos vermelhos e toma a vestimenta } \\
\text { de um homem. }\end{array}$ \\
\hline
\end{tabular}

metro: galiâmbico

44 Note-se a forma Cibēbe, no lugar de Cibĕle, formas usadas em função das necessidades métricas, segundo os contextos. Também por razão métrica, impõe-se a correção de tympano em typano, como em CATUL.63.8-9. No fragmento 6, Mattiacci viu também uma possível influência arcaizante de linha de Ênio: hastis longis campus... horret (Goldber-Manuwald, Scipio, fr. 6, p. 292) (1995, p. 77). 
Esses fragmentos são exemplos de três versos em sequência de um raríssimo poema galiâmbico, metro ligado ao culto de Cibele ${ }^{45}$. O único poema desse tipo que sobrevive inteiro é Catul.63. Assim, também aqui estamos em plena linhagem catuliana. Notemse as correspondências com o vocabulário catuliano, especialmente no fragmento 6 (marcamos em negrito):

\begin{tabular}{|l|l|}
\hline & CATUL.63.27-30 \\
\hline $\begin{array}{l}\text { simul haec comitibus Attis cecinit notha mulier, } \\
\text { thiasus repente linguis trepidantibus ululat, } \\
\begin{array}{l}\text { leue tympanum remugit, caua cymbala } \\
\text { recrepant, } \\
\text { uiridem citus adit Idam properante pede chorus. }\end{array}\end{array}$ & $\begin{array}{l}\text { canta, o tíaso logo ulula em línguas trêmulas, } \\
\text { leve remuge o tímpano, ocos batem címbalos, } \\
\text { lépidos pés depressa o coro ao Ida verde / vai. } \\
\text { (tradução de OLIVA NETO, 1996, p. 117). }\end{array}$ \\
\hline
\end{tabular}

Além dos fragmentos reportados aqui, o único outro exemplo latino de galiambos, para além de CATUl.63, vem de fragmentos da sátira menipeia Eumenides, de Varrão:

\begin{tabular}{|l|l|}
\hline & VAR.Men.131-132 \\
\hline Phrygios per ossa cornus liquida canit anima. & $\begin{array}{l}\text { A flauta frígia ressoa, com um límpido som, } \\
\text { através dos Ossos. }\end{array}$ \\
\hline $\begin{array}{l}\text { tibi tympanon inanis sonitus matris deum } \\
\text { tonimus ... tibi nos, tibi nunc semiuiri } \\
\text { teretem comam uolantem iactant tibi Galli. }\end{array}$ & $\begin{array}{l}\text { por ti fazemos ressoar o tímpano do som } \\
\text { [não?] inane da mãe dos deuses... } \\
\text { por ti nós, por ti agora, semi-homens, } \\
\text { os [sacerdotes] galos jogam por ti a elegante } \\
\text { cabeleira esvoaçante. }\end{array}$ \\
\hline
\end{tabular}

Ainda que em fragmentos, os elementos notadamente tópicos dos galiambos, também se verificam aqui: o tímpano (tympanon... sonimus, em Varrão; sonante ty $[\mathrm{m}]$ panum, em Mecenas), o chacoalhar da cabeça (teretem comam... iactant, em Varrão; quate

\footnotetext{
45 De acordo com Fordyce: "O metro galiâmbico devia seu nome a sua conexão com o culto de Cibele, mas nós não sabemos quando ou como ele se desenvolveu. Em grego, os versos acima citados são os únicos

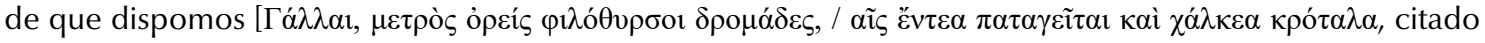
por Hephaestion]. Em latim, Varrão os usou em um ponto apropriado de seus Eumenides, escrito em uma mistura de metros, e Mecenas os usaria no mesmo contexto. A base do metro é uma linha de quatro iônicos a minore, o último catalético, com diérese depois do segundo; resolução em ambas as metades e, na forma latina, anaclasis (em Catulo, regular na primeira metade, rara na segunda: $\mathrm{cf} .73,76$ ) produz seu movimento peculiarmente agitado" (FORDYCE, 1961, p. 263). No original: "The galliambic metre owed its name to its connexion with the cult of Cybele, but how or when it was developed we do not know. In Greek the two lines quoted above are the only galliambics we possess. In Latin Varro had used it at an appropriate point in his Eumenides, which was written in a medley of metres, and Maecenas was to use it in the same context. The basis of the metre is a line of four ionics a minore, the last catalectic, with diaeresis after the second; resolution in both halves and, in the Latin form, anaclasis (in Catullus regular in the first half, rare in the second: see 73, 76), produce its peculiarly agitated movement".
} 
flexibile caput, em Mecenas), além das anáforas hínicas, em admoestações dirigidas à segunda pessoa do singular (tibi... tibi... tibi... tibi, em Varrão; ades... ades, em Mecenas). Diante dessa intensa proximidade entre os galiambos latinos, toda consideração da especificidade do ditado poético de Mecenas desaparece, em face do que parece ser efetiva composição nos limites estritos de um gênero muito específico. Retira-se daí notável advertência contra o psicologismo de certa crítica.

\begin{tabular}{|l|l|}
\hline & 7 [Césio Basso], GLK vi. 262-3 \\
\hline $\begin{array}{l}\text { Siquis quasierit quid ita, cum sit galliambicus } \\
\text { uersus, iambici quoque nomen acceperit, } \\
\text { hoc uersu, qui est apud Maecenatem, lecto } \\
\text { intelleget eum [galliambicum metrum] ex } \\
\text { iambico trimetro nasci: }\end{array}$ & $\begin{array}{l}\text { Se alguém perguntar por que então, embora } \\
\text { seja o verso galiâmbico, também recebeu o } \\
\text { nomé em Mecenas, compreenderá que ele [o } \\
\text { metro galiâmbico] nasce do trímetro iâmbico: }\end{array}$ \\
\hline hic nympha cingit omnis Acheloum senem. & aqui cada ninfa rodeia o velho Aqueloo. \\
\hline
\end{tabular}

metro: trímetro iâmbico

Trata-se, provavelmente, de retomada, bastante próxima, do seguinte verso da llíada:

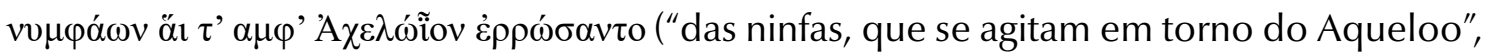
24.616, cf. COURTNEY, 1993, p. 280) ${ }^{46}$. Se for o caso, como parece, a refacção de um verso homérico chama a atenção diante do que parece ser um filo-helenismo bastante marcado na poesia de Mecenas, de verve especificamente alexandrina. É possível que o fragmento fizesse parte do mesmo poema que os fragmentos 5 e 6.

\begin{tabular}{|l|l|}
\hline & 8 Sen. Ep. 92.35: \\
\hline Diserte Maecenas ait: & Mecenas diz expressamente: \\
\hline nec tumulum curo; sepelit natura relictos. & $\begin{array}{l}\text { não me preocupo com um túmulo; a natureza } \\
\text { enterra os abandonados. }\end{array}$ \\
\hline
\end{tabular}

metro: hexâmetro dactílico

Mais um exemplo da "frequente recorrência do pensamento da morte" na poesia de Mecenas (MATTIACCI, 1995, p. 82, tradução nossa) ${ }^{47}$. Mais que uma leitura subjetiva calcada na personalidade de Mecenas, pode-se remeter a motivo neotérico presente em fragmento também hexamétrico de Licínio Calvo: Cum iam fulua cinis fuero ("quando eu já for cinza fulva", HOLLIS, 2007, p. 244; cf. também Hor.Carm.2.20.21.24 e Ov.Pont.3.2.28). Único fragmento elogiado por Sêneca, seria, para Makowski, um “hexâmetro majestoso

46 Com base na referência iliádica, Courtney e Hollis discutem a qual rio Aqueloo Mecenas se refere, concluindo se tratar do Aqueloo na Lídia (COURTNEY, 1993, p. 280; HOLLIS, 2007, p. 324).

47 No original: "il frequente ricorrere del pensiero alla morte". 
- Fragmentos poéticos de Mecenas: tradução e comentário

[...] de que Virgílio teria podido se orgulhar" $\left(1992\right.$, p. 33) ${ }^{48}$, mas a correspondência com Calvo não exclui a possibilidade de que, como na Quintilia de que provém aquele fragmento, possamos estar diante de poesia erótica, especificamente elegíaca (TRAGLIA, 1974, p. 144).

Tampouco se pode excluir a possibilidade de que se trate de um verso satírico; o cemitério é, por exemplo, cenário importante em Hor.Sat.1.8. Sabe-se, ademais, que Mecenas construiu um novo jardim no Esquilino, no lugar de um cemitério, reurbanizando o local, referido na sátira (versos 14-15; cf. GOWERS, 2012, p. 263 e 271). Se for o caso de uma sátira e, novamente, de um diálogo com Horácio, seria caso a se somar ao quanto já dito sobre o fr. 1, acima ${ }^{49}$.

\begin{tabular}{|l|l|}
\hline & $\mathbf{9}$ De Dub. Nom. 591: \\
\hline Tornum generis masculini ut Maecenas: & $\begin{array}{l}\text { Tornum é do gênero masculino, como } \\
\text { Mecenas: }\end{array}$ \\
\hline cardine torno. & uma dobradiça um torno (?). \\
\hline
\end{tabular}

metro: -

O fragmento é, segundo Hollis, "desafiador por mais de uma razão" (HOLLIS, 2007, p. 325, tradução nossa ${ }^{50}$ ), não parecendo perfazer um sintagma.

\begin{tabular}{|l|l|}
\hline & $\mathbf{1 0}$ Diom. GLK I 369: \\
\hline Maecenas: & Mecenas: \\
\hline nexisti rectia lecto & teceste redes no [meu] leito. \\
\hline
\end{tabular}

metro: fim de hexâmetro dactílico

De acordo com Courtney (1993, p. 281) e Hollis, tratar-se-ia de confusão com Prop.3.8.37, "embora uma citação genuína de Mecenas possa ter se perdido na transmissão" (HOLLIS, 2007, p. 325, tradução nossa) ${ }^{51}$. Costa, contudo, pende para considerar a citação genuína (2015, p. 451).

\footnotetext{
48 No original: "majestic hexameter [...] Virgil could have been proud".

49 Essa sugestão, relacionando o fr. 8 com Hor.Sat.1.8, é devida ao parecerista anônimo, a quem agradecemos enfaticamente.

50 No original: "puzzling for more than one reason".

51 No original: "though a genuine quotation from Maecenas could have fallen out".
} 


\begin{tabular}{|l|l|}
\hline & $\mathbf{1 1}$ De Dub. Nom. 588 \\
\hline $\begin{array}{l}\text { Quirites singulari numero caret, nam } \\
\text { (quamquam Keil) Maecenas dixit Quiritem, } \\
\text { sed non recipitur. }\end{array}$ & $\begin{array}{l}\text { Quirites não tem singular, embora Mecenas } \\
\text { diga Quiritem, mas [a forma] não é autorizada. }\end{array}$ \\
\hline
\end{tabular}

metro: -

Segundo Hollis (2007, p. 32552), "dizer que o singular de Quirites não é admitido (non recipitur) não representa corretamente a posição na poesia; o singular ocorre duas vezes em Horácio e quatro vezes em Ovídio [...] Se, no entanto, Mecenas usou o singular na prosa, isso de fato seria único". É por essa especificidade que a citação vai arrolada entre os fragmentos poéticos.

\section{Apêndice: os fragmentos prosaicos de Mecenas}

Costa assinala, com razão, que a prosa de Mecenas foi objeto de muito menos atenção do que sua poesia (2015, p. 451, n. 33). Entretanto, a prosa dessa personagem era sem dúvida vasta, incluindo uma obra (satírica, talvez) intitulada Prometheus, um diálogo com personagens de seu círculo (incluindo Horácio e Virgílio) de nome Symposium, além da obra autobiográfica De cultu suo e do que pode ser tido um panegírico à irmã de Augusto, In Octauiam (MAKOWSKI, 1991, p. 26). Trata-se de material rico também pelo contexto de transmissão, com destaque para um conjunto de epístolas de Sêneca, que constitui a meditação mais aprofundada sobre a escrita de Mecenas legada pela Antiguidade. Conforme anunciado, este apêndice reúne esse material e o traduz, facilitando assim o acesso para investigações futuras.

\begin{tabular}{|c|c|}
\hline & SEN.Ep.19.9 \\
\hline $\begin{array}{l}\text { Volo tibi hoc loco referre dictum Maecenatis } \\
\text { uera in ipso eculeo elocuti: 'ipsa enim altitudo } \\
\text { attonat summa'. Si quaeris in quo libro dixerit, } \\
\text { in eo qui Prometheus inscribitur. Hoc uoluit } \\
\text { dicere, attonita habet summa. Est ergo tanti } \\
\text { ulla potentia ut sit tibi tam ebrius sermo? } \\
\text { Ingeniosus ille uir fuit, magnum exemplum } \\
\text { Romanae eloquentiae daturus nisi illum } \\
\text { eneruasset felicitas, immo castrasset. }\end{array}$ & $\begin{array}{l}\text { Neste lugar, quero te relatar um dito de } \\
\text { Mecenas, coisas verdadeiras que disse no } \\
\text { próprio cavalete:"Pois sua própriaalturafulmina } \\
\text { de raios os cumes". Se perguntas em que livro } \\
\text { o tenha dito, é naquele intitulado Prometheus. } \\
\text { Ele quis dizer: "que faz fulminar de raios os } \\
\text { cumes". Agora, há tamanho poder que seria } \\
\text { capaz de tornar teu discurso tão ébrio? Aquele } \\
\text { homem tinha engenho e teria fornecido um } \\
\text { grande exemplo de eloquência romana, se a } \\
\text { prosperidade não lhe tivesse tirado a nervatura, } \\
\text { ou antes não o tivesse castrado. }\end{array}$ \\
\hline
\end{tabular}

52 No original: "To say that the singular of Quirites 'is not admitted' ('non recipitur') somwhat misrepresents the position in poetry; the singular occurs twice in Horace and four times in Ovid [...]. If, however, Maecenas used the singular in prose, that would indeed be unique". 


\begin{tabular}{|c|c|}
\hline & SEN.Ep.101.10-13 \\
\hline $\begin{array}{l}\text { [10] Ideo propera, Lucili mi, uiuere, et singulos } \\
\text { dies singulas uitas puta. Qui hoc modo se } \\
\text { aptauit, cui uita sua cotidie fuit tota, securus } \\
\text { est: in spem uiuentibus proximum quodque } \\
\text { tempus elabitur, subitque auiditas et miserrimus } \\
\text { ac miserrima omnia efficiens metus mortis. } \\
\text { Inde illud Maecenatis turpissimum uotum, quo } \\
\text { et debilitatem non recusat et deformitatem et } \\
\text { nouissime acutam crucem, dummodo inter } \\
\text { haec mala spiritus prorogetur: }\end{array}$ & $\begin{array}{l}\text { [10] Assim, meu Lucílio, apressa-te a viver e } \\
\text { considera cada dia como uma vida. Quem } \\
\text { assim se moldou, para quem sua vida } \\
\text { cotidianamente foi toda ela, está a salvo: para } \\
\text { os que vivem da esperança do porvir, cada } \\
\text { tempo escapa, a avidez os toma, assim como } \\
\text { o infelicíssimo medo da morte, causador de } \\
\text { todas as infelicidades. Daí aquele desejo tão } \\
\text { abjeto de Mecenas, pelo qual não recusa a } \\
\text { fraqueza, a deformidade e, enfim, uma cruz } \\
\text { pontiaguda, desde que, em meio a tais males, } \\
\text { o seu sopro seja prorrogado: }\end{array}$ \\
\hline $\begin{array}{r}\text { [11] debil } \\
\text { debile } \\
\text { tuber ad } \\
\text { lubricc } \\
\text { uita dum } \\
\text { hanc } n \\
\text { si sedear }\end{array}$ & $\begin{array}{l}\text { [11] faze-[me] impotente na mão, } \\
\text { impotente no pé, manco, } \\
\text { erige um tumor em uma corcunda, } \\
\text { chacoalha os dentes [até que fiquem] bambos: } \\
\text { enquanto resta vida, está [tudo] bem; } \\
\text { protege-ma, mesmo que eu } \\
\text { esteja posto em uma cruz pontiaguda. }\end{array}$ \\
\hline $\begin{array}{l}\text { [12] Quod miserrimum erat, si incidisset, } \\
\text { optatur, et tamquam uita petitur supplicii mora. } \\
\text { Contemptissimum putarem, si uiuere uellet } \\
\text { usque ad crucem: } \\
\text { 'tu uero' inquit 'me debilites licet, dum spiritus } \\
\text { in corpore fracto et inutili maneat; depraues } \\
\text { licet, dum monstroso et distorto temporis } \\
\text { aliquid accedat; suffigas licet et acutam sessuro } \\
\text { crucem subdas': est tanti uulnus suum premere } \\
\text { et patibulo pendere districtum, dum differat id, } \\
\text { quod est in malis optimum, supplicii finem? est } \\
\text { tanti habere animam, ut agam? }\end{array}$ & $\begin{array}{l}\text { [12] Ele deseja o que haveria de pior se ocorresse } \\
\text { e, como se fosse vida, pede uma extensão do } \\
\text { suplício. Eu o consideraria o mais abjeto dos } \\
\text { homens se quisesse viver até a cruz: } \\
\text { tu pois, diz ele, podes me estropiar, desde que um } \\
\text { sopro permaneça no corpo quebrado e inútil; tu } \\
\text { podes me deformar, desde que algum tempo seja } \\
\text { acrescido para o monstruoso e disforme; tu podes } \\
\text { me amarrar e prover a mim que hei de ser posto } \\
\text { nela uma cruz pontiaguda: } \\
\text { Vale a pena apertar a sua ferida e ficar suspenso, } \\
\text { amarrado, no patíbulo, tão longamente quanto } \\
\text { difira aquilo que é excelente nos males, o fim } \\
\text { do suplício? Vale tanto manter o sopro, para } \\
\text { entregá-lo? }\end{array}$ \\
\hline $\begin{array}{l}\text { [13] Quidhuic optes } \mathrm{n} \\
\text { sibi uult ista carminis } \\
\text { quid timoris dementis } \\
\text { foeda uitae mendicatio } \\
\text { recitasse Vergilium: }\end{array}$ & $\begin{array}{l}\text { [13] O que desejarás para ele a não ser que os } \\
\text { deuses atendam? O que quer dizer essa torpeza } \\
\text { de uma canção afeminada? O que [quer dizer] } \\
\text { esse pacto de um temor tão enlouquecido? O } \\
\text { que [quer dizer] uma mendicância tão vil de } \\
\text { vida? Julgarás que para ele certa vez recitou } \\
\text { Virgílio: }\end{array}$ \\
\hline usque adeone mori miserum est? (A.12.646) & é a tal ponto infeliz morrer? \\
\hline $\begin{array}{l}\text { Optat ultima malorum et, quae pati } \\
\text { grauissimum est, extendi ac sustineri cupit: qua } \\
\text { mercede? scilicet uitae longioris. Quod autem } \\
\text { uiuere est diu mori? }\end{array}$ & $\begin{array}{l}\text { Deseja os males extremos e quer que se } \\
\text { estendam e se sustentem aqueles que são mais } \\
\text { dolorosos de sofrer: por qual recompensa? A } \\
\text { de uma vida mais longa. Um viver que é, no } \\
\text { entanto, morrer longamente? }\end{array}$ \\
\hline
\end{tabular}




\begin{tabular}{|c|c|}
\hline & Sen.Ep.114.4-8 \\
\hline $\begin{array}{l}\text { [4] Quomodo Maecenas uixerit notius est } \\
\text { quam ut narrari nunc debeat, quomodo } \\
\text { ambulauerit, quam delicatus fuerit, quam } \\
\text { cupierit uideri, quam uitia sua latere noluerit. } \\
\text { Quid ergo? non oratio eius aeque soluta est } \\
\text { quam ipse discinctus? non tam insignita illius } \\
\text { uerba sunt quam cultus, quam comitatus, } \\
\text { quam domus, quam uxor? Magni uir ingenii } \\
\text { fuerat si illud egisset uia rectiore, si non uitasset } \\
\text { intellegi, si non etiam in oratione difflueret. } \\
\text { Videbis itaque eloquentiam ebrii hominis } \\
\text { inuolutam et errantem et licentiae plenam. } \\
\text { [Maecenas de cultu suo.] }\end{array}$ & $\begin{array}{l}\text { [4] De que modo Mecenas tenha vivido é } \\
\text { bem conhecido para que eu agora precise } \\
\text { contar como andava, o quanto era delicado, } \\
\text { o quanto desejava ser visto, o quanto não } \\
\text { queria expor os seus vícios. O que então? O } \\
\text { discurso dele não é tão frouxo quanto ele } \\
\text { mesmo [era] desprovido de cinto? Não são } \\
\text { tão características dele as palavras quanto o } \\
\text { modo de viver, a companhia, a casa, a mulher? } \\
\text { Ele teria sido um homem de grande engenho } \\
\text { se tivesse perseguido um caminho mais reto, } \\
\text { se não tivesse evitado ser compreendido, se, } \\
\text { também no discurso, nãotivesse se derramado. } \\
\text { Verás, pois, a eloquência embrulhada do } \\
\text { homem ébrio, [a eloquência] errante e cheia } \\
\text { de licensiosidade. [Mecenas, na obra Sobre o } \\
\text { seu modo deviver] }\end{array}$ \\
\hline $\begin{array}{l}\text { [5] Quid turpius } \\
\text { 'amne siluisque ripa comantibus'? }\end{array}$ & $\begin{array}{l}\text { [5] O que há de mais torpe do que: } \\
\text { na margem do rio e nas florestas cabeludas? }\end{array}$ \\
\hline $\begin{array}{l}\text { Vide ut } \\
\text { 'alueum lyntribus arent uersoque uado } \\
\text { remittant hortos'. }\end{array}$ & $\begin{array}{l}\text { Veja como: } \\
\text { arem o leito em esquifes e, tendo dado a volta no } \\
\text { encalho, abandonem os jardins. }\end{array}$ \\
\hline $\begin{array}{l}\text { Quid? si quis } \\
\text { 'feminae cinno crispat et labris columbatur } \\
\text { incipitque suspirans, ut ceruice lassa fanantur } \\
\text { nemoris tyranni'. }\end{array}$ & $\begin{array}{l}\text { O quê? Se alguém: } \\
\text { franze com uma careta feminina, arrulha pelos } \\
\text { lábios e começa a suspirar, como os senhores do } \\
\text { bosque agindo freneticamente, com a cabeça } \\
\text { largada. }\end{array}$ \\
\hline $\begin{array}{l}\text { 'Inremediabilis factio rimantur epulis } \\
\text { lagonaque temptant domos et spe mortem } \\
\text { exigunt.' }\end{array}$ & $\begin{array}{l}\text { A turba fatal fareja por comida, cerca as casas } \\
\text { com o caneco e inflige a morte com esperança. }\end{array}$ \\
\hline 'Genium festo uix suo testem.' & O Gênio raramente é testemunha em sua festa. \\
\hline 'Tenuisue cerei fila et crepacem molam.' & Ou fios de cera esguia e um moinho barulhento. \\
\hline 'Focum mater aut uxor inuestiunt.' & A mãe ou a mulher vestem o fogareiro. \\
\hline
\end{tabular}


[6] Non statim, cum haec legeris, hoc tibi occurret, hunc esse, qui solutis tunicis in urbe semper incesserit (nam etiam cum absentis Caesaris partibus fungeretur, signum a discincto petebatur); hunc esse, qui $<$ in $>$ tribunali, in rostris, in omni publico coetu sic apparuerit, ut pallio uelaretur caput exclusis utrimque auribus, non aliter, quam in mimo fugitiui diuitis solent; hunc esse, cui tunc maxime ciuilibus bellis strepentibus et sollicita urbe et armata comitatus hic fuerit in publico: spadones duo, magis tamen uiri quam ipse; hunc esse, qui uxorem milliens duxit, cum unam habuerit?

\section{[7] Haec uerba tam inprobe structa,} tam neglegenter abiecta, tam contra consuetudinem omnium posita ostendunt mores quoque non minus nouos et prauos et singulares fuisse. Maxima laus illi tribuitur mansuetudinis: pepercit gladio, sanguine abstinuit, nec ulla alia re, quid posset, quam licentia ostendit. Hanc ipsam laudem suam corrupit istis orationis portentosissimae delicis; apparet enim mollem fuisse, non mitem.

[8] Hoc istae ambages compositionis, hoc uerba transuersa, hoc sensus miri, magni quidem saepe, sed eneruati, dum exeunt, cuiuis manifestum facient: motum illi felicitate nimia caput. Quod uitium hominis esse interdum, interdum temporis solet.
[6] Não te ocorrerá, imediatamente, ao ler essas frases, ser este aquele que sempre andava na cidade com as túnicas soltas (pois, quando desempenhava o papel de César, ausente, obedecia-se ao não cingido); ser este aquele que, no tribunal, nas tribunas, em toda reunião pública, aparecia de modo que, com o pálio, cobria a cabeça, exceto ambas as orelhas, de modo não diverso de como costumam [se vestir] os fugitivos do rico no teatro; ser este aquele para quem, quando as guerras civis ressoavam mais fortemente e a cidade estava agitada e armada, eram companhia, em público, dois eunucos, mais homens, entretanto, que ele; ser este aquele que se casou mil vezes, embora tenha tido uma única esposa?

[7] Estas palavras, construídas de forma tão extravagante, lançadas de modo tão negligente, dispostas tão contrariamente ao costume de todos, mostram que também os costumes foram não menos novos, pervertidos e anódinos. O maior elogio a ele atribuído é o da mansidão: poupou-se da espada, abstevese do sangue, nem mostrou o que pudesse fazer a respeito de qualquer coisa, afora a libertinagem. Com essa devassidão de um discurso demasiado extravagante, mesmo esse seu elogio mostra, pois, ter sido frouxo, não pacífico.

[8] Esses enigmas de composição, as palavras desviadas, as ideias grandiosas, espantosas, com efeito, mas frequentemente debilitadas ao se expressar, fá-lo-ão manifesto a quem quer que seja: uma cabeça movida para a fecundidade desmedida. Esse vício às vezes costuma ser do homem, às vezes de sua época. 


\begin{tabular}{|l|l|}
\hline & SERV.A.8.310 \\
\hline FACILESQUE OCULOS FERT OMNIA CIRCUM physici & tudo em volta torna os olhos movediços: os \\
dicunt ex uino mobiliores oculos fieri: Plautus & médicos dizem que os olhos se tornam mais \\
"faciles oculos habet", id est mobiles uino. & móveis em razão do vinho. Plauto tem faciles \\
hoc etiam Maecenas in symposio, ubi Vergilius & oculos, isto é, [olhos] móveis pelo vinho. Isso \\
et Horatius interfuerunt, cum ex persona & ainda afirma Mecenas no Symposium, onde \\
Messalae de ui uini loqueretur, ita: "ut idem & Virgílio e Horácio estavam presentes, quando \\
umor ministrat faciles oculos, pulchriora reddit & se fala da força do vinho pela personagem \\
omnia et dulcis iuuentae reducit bona". & de Messala: "esse líquido entrega olhos \\
& movediços, torna tudo mais belo e traz de \\
& volta os bens da doce juventude". \\
\hline
\end{tabular}

\begin{tabular}{|l|l|}
\hline & PRISC. GLK 2, 356, 6-7 \\
\hline $\begin{array}{l}\text { Maecenas in Octauiam: "pexisti capillum } \\
\text { naturae muneribus gratum". }\end{array}$ & $\begin{array}{l}\text { Mecenas, In Octauiam: "Penteaste o cabelo, } \\
\text { devedor dos bens da natureza." }\end{array}$ \\
\hline
\end{tabular}

\begin{tabular}{|c|c|}
\hline & QUINT.Inst.9.4.28 \\
\hline $\begin{array}{l}\text { Quaedam uero transgressiones et longae sunt } \\
\text { nimis, ut superioribus diximus libris, et interim } \\
\text { etiam compositione uitiosae, quae in hoc } \\
\text { ipsum petuntur, ut exultent atque lasciuiant, } \\
\text { quales illae Maecenatis: 'sole et aurora rubent } \\
\text { plurima'; 'inter sacra mouit aqua fraxinos'; } \\
\text { 'ne exequias quidem unus inter miserrimos } \\
\text { uiderem meas' (quod inter haec pessimum est, } \\
\text { quia in re tristi ludit compositio). }\end{array}$ & $\begin{array}{l}\text { Mas certas transposições são demasiado } \\
\text { longas, como nós dissemos nos livros } \\
\text { precedentes, e às vezes mesmo viciosas } \\
\text { no que respeita à composição, e elas são } \\
\text { buscadas exatamente por essa razão, para } \\
\text { que regozijem e divirtam, como aquelas de } \\
\text { Mecenas: eles enrubescem sob o sol e a mais } \\
\text { plena aurora; entre os freixos, a água agitou as } \\
\text { coisas sagradas; nem mesmo os meus funerais } \\
\text { veja eu, o mais infeliz de todos (entre essas, a } \\
\text { última é a pior, pois a composição brinca em } \\
\text { um assunto triste). }\end{array}$ \\
\hline
\end{tabular}

\section{Agradecimentos}

O autor gostaria de agradecer aos pareceristas anônimos pelas correções e valiosíssimas sugestões que generosamente nos ofertaram. O texto se beneficiou muito de seus comentários precisos e eruditos. Evidentemente, todos os defeitos remanescentes são de nossa inteira responsabilidade.

\section{Referências}

\section{Edições de autores antigos e comentários}

ASTBURY, R. (ed.). Marcus Terrentius Varro: Saturarum Menippearum Fragmenta. 2. ed. Münich/Leipzig/Saur: De Gruyter, 2002. 
- Fragmentos poéticos de Mecenas: tradução e comentário

BLÄNSDORF J. (ed.). Fragmenta Poetarum Latinorum Epicorum et Lyricorum, praeter Enni Annales et Ciceronis Germanicique Aratea. 4. ed. New York: De Gruyter, 2011.

COURTNEY, E. The Fragmentary Latin Poets. Oxford: Oxford University Press, 1993.

FINK, G. (ed., trad. e notas). L. Annaeus Seneca: Epistulae morales ad Lucilium, Briefe an Lucilius, Band I. Düsseldorf: Artemis \& Winckler, 2007.

FORDYCE, C. J. (ed., intr. e notas). Catullus: a commentary. Oxford: Oxford University Press, 1961.

GOWERS, E. (ed., intr. e notas). Horace: Satires, book I. Cambridge: Cambridge University Press, 2012.

HOLLIS, A. S. (ed., trad, intr. e notas). Fragments of Roman Poetry. Oxford: Oxford University Press, 2007.

KASTER, R. A. (ed.). C. Suetoni Tranquilli de Vita Caesarum libros VIII et de Grammaticis et Rhetoribus Librum. Oxford: The Clarendon Press, 2016.

KASTER, R. A. (ed., trad., intr. e notas). Macrobius: Saturnalia, books 1-2. Cambridge, Ma/ London: Harvard University Press, 2011.

MERRILL, E. T. (ed. e notas). Catullus. Boston et alibi: Ginn and Company, 1893.

MEYER, W. (ed.). Pomponii Porphyrionis Commentarii in Q. Horatium Flaccum. Leipzig: Teubner, 1874.

MYNORS, R. A. B. (ed.). C. Valerii Catulli Carmina. Oxford: The Clarendon Press, 1958.

NICKEL, R. (ed., trad. e notas). L. Annaeus Seneca: Epistulae morales ad Lucilium, Briefe an Lucilius, Band II. Düsseldorf: Artemis \& Winckler, 2009.

NISBET, R. G. M.; HUBBARD, M. A Commentary on Horace: Odes, Book II. Oxford, Clarendon Press, 1991.

OLIVA NETO, J. A. (trad., introd. e notas). O livro de Catulo. São Paulo: EDUSP, 1996. 
ROSTAGNI, A (ed. e notas). Suetonio: De Poetis e biografi minori. Torino: Loescher, 1944.

SHACKLETON-BAILEY, D. R. (ed.). Horatius: opera. 4.ed. Berlin/New York: De Gruyter, 2008.

THILO, G.; HAGEN, H. (ed.). Servii grammatici qui feruntur in Vergilii carmina commentarii. Leipzig: Teubner, 1881-1902. $3 \mathrm{v}$.

TRAGLIA, A. Poetae novi. 2. ed. Roma: Ateneo, 1974.

WINTERBOTTOM, M. M. Fabi Quintiliani Institutionis Oratoriae Libri Duodecim: tomus II, libri VII-XII. Oxford: The Clarendon Press, 1970.

\section{Estudos modernos}

ANDRÉ, J.-M. Mécène écrivain (avec, en appendice, les fragments de Mécène). In: TEMPORINI, N.; HAASE, W. (ed.). Aufstieg und Niedergang der römischen Welt: Geschichte und Kultur Roms im Spiegel der neueren Forschung, Principat, 30.3. Berlin/ New York: De Gruyter, 1983. p. 1765-1787.

ANDRÉ, J.-M. Mécène: essai de biographie spirituelle. Paris: Les Belles Lettres, 1967.

AVALLONE, R. Mecenate. Napoli: Libreria Scientifica, 1962.

BRADSHAW, A. Some stylistics oddities in Horace, Odes III 8. Philologus, v. 114, p. 145150, 1970.

COSTA, S. Maecenas between apologies and anthologies: past scholarship and new researches. Acta Antiqua Academiae Scientiarum Hungaricae, v. 55, p. 443-456, 2015.

COSTA, S. Un secolo di interpretazioni su un epigramma di Mecenate (fr. 1 Lunderstedt). ACME - Annali della Facoltà di Lettere e Filosofia dell'Universitè degli Studi di Milano, v. 62 , n. 3, p. 307-324, 2009. 
- | Fragmentos poéticos de Mecenas: tradução e comentário

GRANAROLO, J. L'époque néotérique ou la poésie romaine d'avant-garde au dernier siècle de la République (Catulle excepté). In: TEMPORINI, H. (ed.). Aufstieg und Niedergang der römischen Welt: Geschichte und Kultur Roms im Spiegel der neuren Forschung, I, zweiter Band. Berlin/New York: De Gruyter, 1972. p. 278-360.

GRANAROLO, J. D'Ennius à Catulle. Paris: Les Belles Lettres, 1971.

HASEGAWA, A. A arte de ensinar a arte em Horácio. Estado da Arte, São Paulo, 10 nov. 2019. Disponível em: https://estadodaarte.estadao.com.br/a-arte-de-ensinar-a-arte-emhoracio/. Acesso em: 15 jun. 2021.

HASEGAWA, A. A poesia lírica de Horácio. Estado da Arte, São Paulo, 18 nov. 2018. Disponível em: https://estadodaarte.estadao.com.br/a-poesia-lirica-de-horacio/. Acesso em: 15 jun. 2021.

KÓRIZS, I. Maecenas Poeta. Acta Classica Universitatis Sientiarum Debreceniensis, v. 43, p. 51-56, 2007.

MAKOWSKI, J. F. Iocosus Maecenas: patron as writer. Syllecta Classica, v. 3, p. 25-35, 1992.

MATTIACCI. L'attività poetica di Mecenate tra neoterismo e novellismo. Prometheus: rivista di studi classici, v. 21, p. 67-86, 1995.

MIRMONT, H. de la V. de. Études sur l'ancienne poésie latine. Paris: Fontemoig, 1903.

RODRÍGUEZ-PANTOJA, M. El fragmento poético número 1 de Maecenas, Habis, v. 4, 1973, p. 105-113.

COMO CITAR ESTE ARTIGO: AUBERT, Eduardo Henrik. Fragmentos poéticos de Mecenas: tradução e comentário. Revista do GEL, v. 18, n. 2, p. 9-34, 2021. Disponível em: https://revistadogel.gel.org.br/

Submetido em: 19/06/2021 | Aceito em: 09/07/2021. 